\title{
Subspecies in Przewalski's gazelle Procapra przewalskii and its conservation implication
}

\author{
MARDAN Turghan ${ }^{1,2,3}$, JIANG ZhiGang ${ }^{1 *}$, GROVES Colin $\mathrm{P}^{4}$, YANG Ji ${ }^{1} \&$ FANG HongXia ${ }^{1}$ \\ ${ }^{1}$ Key Laboratory of Animal Ecology and Conservation Biology, Institute of Zoology, Chinese Academy of Sciences, Beijing 100101, China; \\ ${ }^{2}$ Key Laboratory of Biogeography and Bioresource in Arid Land, Xinjiang Institute of Ecology and Geography, Chinese Academy of Sciences, \\ Urumqi 830011, China; \\ ${ }^{3}$ Graduate School of Chinese Academy of Sciences, Beijing 100049, China; \\ ${ }^{4}$ Department of Archaeology and Anthropology, Australian National University, Canberra ACT 0200, Australia
}

Received July 10, 2012; accepted October 24, 2012

\begin{abstract}
Przewalski's gazelle Procapra przewalskii is an endangered species endemic to China. A question remains about subspecific variation in this species. Skulls of Przewalski's gazelle collected from its current remnant ranges around the Qinghai Lake in combination with those collected prior to the 20th century were measured and analyzed using Hierarchical Cluster Analysis in order to clarify the question. Unexpectedly, P. p. diversicornis, extirpated from its historic range, has spread to the Qinghai Lake region where it has replaced nominotypical P. p. przewalskii and is now restricted to a few small isolated populations around the lake. We discuss the causes of this unexpected replacement. In this study, we discuss the possibility of a new form, possibly a new subspecies, in the Guide Basin, adjacent to Qinghai Lake; it is unclear whether the new form has long existed and was only discovered in recent years, or whether it evolved in recent times due to the geographical isolation and anthropogenic landscape features. The study sheds light on the processes of microevolution and subspeciation in Procapra przewalskii, and based on the findings, we propose measures for conservation strategies for Przewalski's gazelle.
\end{abstract}

Przewalski's gazelle, Procapra przewalskii, the Qinghai Lake, skull, Procapra przewalskii wayu, evolutionarily significant units

Citation: Mardan T, Jiang Z G, Groves C P, et al. Subspecies in Przewalski's gazelle Procapra przewalskii and its conservation implication. Chin Sci Bull, 2013, 58: 1897-1905, doi: 10.1007/s11434-013-5731-4

Przewalski's gazelle Procapra przewalskii is endemic to China and a flagship species in the ecosystem of the Qinghai-Tibetan Plateau [1,2]. The historical distribution of the species once covered parts of Gansu (Kansu) Province and Qinghai Province, and possibly included parts of Inner Mongolia Autonomous Region and Ningxia Hui Autonomous Region [3]. As a result of human activities, its population has declined steeply; it has been affected by severe habitat destruction and it is now restricted to isolated populations around the Qinghai Lake (Kukunor) in the northeast part of Qinghai Province [4]. It was once considered to be the world's rarest antelope by Mallon and Kingswood [5], with only 300 remaining in the mid-1990s [6-8]. Though it

*Corresponding author (email: jiangzg@ioz.ac.cn) is possible that remnant populations still survive outside the Qinghai Lake region, there have been no recent records. A survey carried out from 5 June to 7 July 1996 failed to find any sign of the species in western Inner Mongolia and adjacent Gansu [9,10]. We did not find any Przewalski's gazelle in our joint surveys with Russian scientists in Inner Mongolia and Ningxia in 2000 and 2003, either [1]. Consequently, the critical status of this gazelle has aroused attention world-wide and it was listed as Critically Endangered in the Redlist of the Species Survival Commission of the IUCN [11]. A recent survey indicated that the population of the species is increasing although, because of the extreme fragmentation of its habitat, it is still threatened with extinction [12].

Przewalski's gazelle was first collected by the Russian 
explorer Anton Nikolay Przewalsky, who brought back the specimens from the valley of the Chagry-Gol (=Datunkhe River, about $50 \mathrm{~km}$ north of Qinghai Lake) to St. Petersburg in 1875 [1]. The species was at first mistakenly thought to be the Mongolian gazelle and was ascribed to Antelope gutturosa by Przewalsky, but in 1881 he described it as a new species under the name Antilope cuvieri. Later in the same year, Büchner renamed it Gazella przewalskii because the name cuvieri had already been used for a different gazelle species in Northern Africa. It was referred to the subgenus Procapra by Lydekker and Blaine[13]; this subgenus, originally described as a distinct genus (for the Tibetan gazelle, $P$. picticaudata, by Hodgson, 1846) was restored to generic rank by Allen [3]. Ellerman and Morrison-Scott [14] placed przewalskii as a subspecies of Procapra picticaudata Hodgson (1846); but later Stroganov [15] pointed out that the two species differ strongly, and were marginally sympatric, and Chinese scientists confirmed that Przewalski's gazelle does indeed live sympatrically with the Tibetan gazelle on the northern shore of the Qinghai Lake [16]. Recent surveys found that the Tibetan and Przewalski's gazelle still live in the steppe ecosystem in a valley of the Upper Buha River [1]. Although the two species do share morphological similarities, there are distinct differences in the shape of the horns as well as the structure of the skull; molecular data $[17,18]$ suggest that $P$. przewalskii may in fact be more closely related to the Mongolian gazelle, $P$. gutturosa, than to $P$. picticaudata. Recent molecular evidences supported the hypothesis.

Stroganov [15] also found that P. przewalskii (which he in fact referred to the genus Gazella) was itself polytypic, and described a new subspecies Gazella przewalskii diversicornis, from Gansu. Groves [19] recognized this (under the name Procapra przewalskii diversicornis) as a distinctive race of larger size and darker, more reddish color, with more spreading horns with less incurved tips. The original specimens, eight adult males and one juvenile male, were collected by Pyotr Kuzmich Kozlov in 1909 at an oasis of Shin-zhin-pu (this is perhaps Xincheng, $36^{\circ} 10^{\prime} \mathrm{N}, 103^{\circ} 29^{\prime} \mathrm{E}$ ). Groves [19] found another specimen in the Natural History Museum in London from S. W. Gobi, and the specimen had been collected by George Fenwick Owen in 1911. The circumstances were described by Wallace [20], who said that the locality was Shiakou, "about half way between Liangchow [now Wuwei] and Kanchow now [Zhangye]. Shiakou, a small village along the Great Wall, is at $38^{\circ} 15^{\prime} \mathrm{N}, 101^{\circ}$ 50 'E.

Groves [19] listed a few additional features of the subspecies, namely the comparatively abbreviated braincase length and greater sexual dimorphism. We note that, under the Phylogenetic Species Concept more recently employed by Groves [21], these two "subspecies" would almost certainly rank as distinct species, in that they have nonoverlapping ranges of morphological variation [22].

During our 18 years of intense field survey on the Prze- walski's gazelle, we noticed that the form of horns of individuals seen in the areas around the Qinghai Lake is exactly that ascribed to $P$. p. diversicornis rather than that of nominotypical P. p. przewalskii for which Qinghai is the terra typica [1]. On the other hand, we analyzed two museum skulls collected on Bird Island in the 1990s, as well as one which had originally been collected by Przewalsky and stored in the Institute of Zoology, Russian Academy of Sciences (RAS), and those skulls, by contrast, bore close resemblance to nominotypical $P$. p . przewalskii: the tips of the horns of these skulls are strongly curved up, even in one case with one tip overlapping the other. Yet, we have never been able to detect any individual of this kind during our field surveys [1]. The puzzle about the subspecies in the Przewalski's gazelle therefore remains.

The purpose of the paper is to clarify this subspecies conundrum in Przewalski's gazelle. Taking into account the role of geographical isolation on morphological variation, we mainly focus our analysis on the cranial measurements of adult males from different localities around the Qinghai Lake. Finally, by combining the results of our previously published studies, we attempt to answer the question whether there are truly two taxa (species or subspecies) within Przewalski's gazelle and, if the answer is yes, then what are their exact distributions: Is it possible that the two taxa live, or once lived, sympatrically in the Qinghai Lake region? Which factors shaped the evolutionary history and distribution patterns of the taxa? It is hoped that this study will provide a scientific basis for the development of conservation strategies for Przewalski’s gazelle.

\section{Study area}

The study was carried out around the Qinghai Lake $\left(99^{\circ} 36^{\prime}-100^{\circ} 47^{\prime} \mathrm{E}, 36^{\circ} 32^{\prime}-37^{\circ} 15^{\prime} \mathrm{N}\right)$. Our study area consists of high altitude steppe and desert habitat, ranging from 2850-5826 $\mathrm{m}$ above sea level, with an average elevation of $3800 \mathrm{~m}$. The climate is characterized by dry, cold winters, strong winds, high levels of solar radiation, a wide range of temperature between day and night, a short frost-free period, low precipitation and high evaporation. Annual precipitation varies from $360 \pm 370 \mathrm{~mm}$ in the northwest to $395 \pm 412$ $\mathrm{mm}$ in the southeast while the annual evapotranspiration is about four times greater. Annual temperatures range from $-31^{\circ} \mathrm{C}$ in January to $28^{\circ} \mathrm{C}$ in July; the recorded lowest temperature is $-41^{\circ} \mathrm{C}$. The study area is a mosaic of four types of vegetation: steppe, desert shrub, alpine shrub and alpine meadow. Steppe is mainly found in the east, north and northwest parts of the region at 3000-3600 m. In the east, the dominant plant species are Achnatherum splendens, Leymus secalinus and Stipa krylorii, whereas in the north and northwest the environment is dominated by Stipa purpurea and Carex spp. Desert shrub is distributed mainly in the northeast at 3100-3200 m, with the dominant plants, 
Ephedra intermedia and Artemisia desertorum. Alpine shrub, dominated by Sabina vulgaris and Salix oritreoha, occurs at 3450-3650 $\mathrm{m}$ in the mountains around the lake. Alpine meadows, being found on the wetland of the south and west shores of the lake, is dominated by Blysmus sinocompressus. The lake, except for the delta of the Buha River on the west shore, is frozen from December to March. It is extremely windy in winter and early spring [6]. A tendency towards drier and warmer climate during the past 100 years [23] , combined with human activities, has caused a drop in water level of this China's largest inland semi-salt water lake, by $3.35 \mathrm{~m}$ during the most recent 30 years [24].

The main obstacle to determining the pattern of variation in a species is the availability of samples that are sufficiently large and random with respect to locality [25]. We conducted field surveys and collected 21 skulls of male gazelles, all victims wolf predation or natural death, in all known distribution sites of the gazelle around the lake (Figure 1) as follows.

The Hudong-Ketu desert population. The desert stretches from the northeastern to the northern shore of the lake, and the Hudong-Ketu population of the Przewalski's gazelle (HUDONG) lives there in the ecotone between the steppe and desert.

Yuanzhe moraine population. The moraine is a typical steppe grassland with a minimum distance of 15-20 km from the Hudong-Ketu desert, but the Yuanzhe population (YAUNZHE) and the Hudong population is separated by pasture fences, roads and residential areas newly construct- ed during the past two decades.

Bird Island population. The island was once an island where tens of thousands of bar-headed geese bred in summer in 1950s, but it is now a peninsula with a vast sandy beach as a result of the falling water level in the Qinghai Lake. The Bird Island National Natural Reserve was established in the mid-1970s to protect the breeding grounds of migratory birds. A population of the gazelle (BIRD I) lives within the reserve, in the ecotone between steppe and desert.

The Qieji population (QIEJI) and Wayu population (WAYU) are found in pastures of Qieji village and Wayu farm, on the typical ecotone between temperate semiarid steppe and desert in the eastern edge of the Chaidam Basin. These two populations, which are surrounded by high mountains (Xiangpi Mountain, Qilian Mountain and Burhan Buddah Mountain), were unknown at the time of Jiang et al.'s [26] field survey, or even as recently as Lei et al.'s [27] genetic study. There are anthropogenic landscape features such as roads, residential areas, farms and abandoned villages between the two.

The Ganzihe population (GANZIHE) and Hargai population (HARGAI) are distributed on the north shore of the lake. The habitat of the Ganzihe population is a mosaic of steppe, desert and wetland, while the Hargai population lives in a vast area of steppe less than $40 \mathrm{~km}$ away from Ganzihe. In this study, they are combined into a single Hargai population (the Gahai population of Lei et al. [27]), as there are no robust geographical barriers between the two,

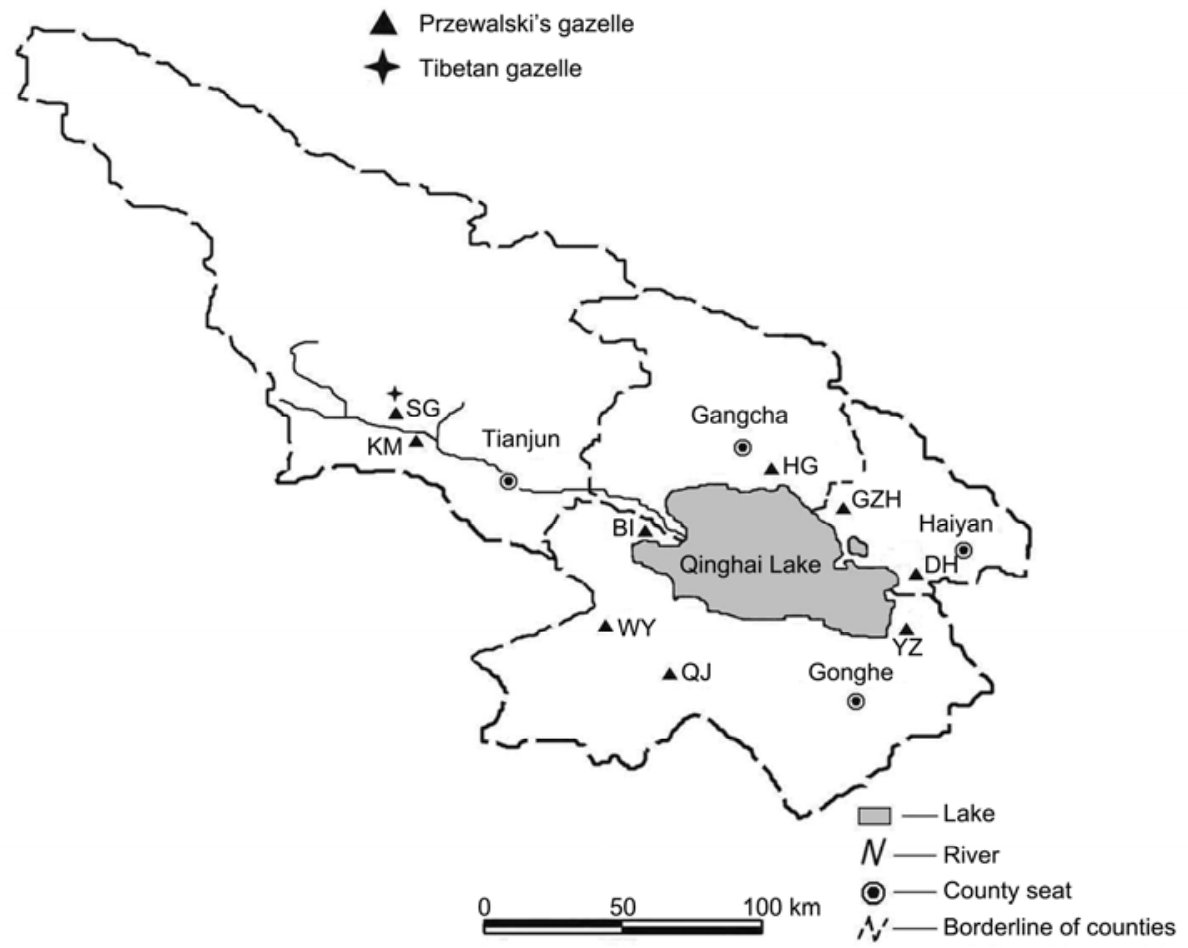

Figure 1 The sampling sites of Przewalski's gazelle around the Qinghai Lake and along the Buha River. HD-Hudong-Ketu desert; YZ-Yuanzhe farm; QJ-Qieji village; WY-Wayu farm; BI-Bird Island; GZH-Ganzihe village; HG-Hargai village; KM-Kuarma village; SG-Shengge village. 
and the genetic evidence shows that there are still a few individual exchanges between the populations [18].

The Kaurma population and Shengge population are treated as the Tianjun population (TIANJUN) in our study. Like the Qieji and Wayu populations, their existence was unknown at the time of the studies of Jiang et al. [26] and Lei et al. [27]. Tibetan gazelle were found in the upper course of the Buha river ("Bukhain-Gol" of Stroganov [15] and other Russian authors) [15]. Being a part of the southern Qilian Mountains, this area is up to $5826 \mathrm{~m}$ above sea level, and winters are extremely cold.

\section{Methods}

\subsection{Cranial measures}

Only the skulls of adult Przewalski's gazelle were measured in order to avoid the age differences. The cranial characters measured in this study included:

(i) Horn Length (HL),

(ii) Tip to Tip (TIP) Distance,

(iii) Greatest Width across Horns (SPAN),

(iv) Length of Nasal Bone along internasal suture (NASL),

(v) Skull Length (SL),

(vi) Greatest Skull Length (GTL),

(vii) Greatest Breadth (GTBR) (Figure 2).

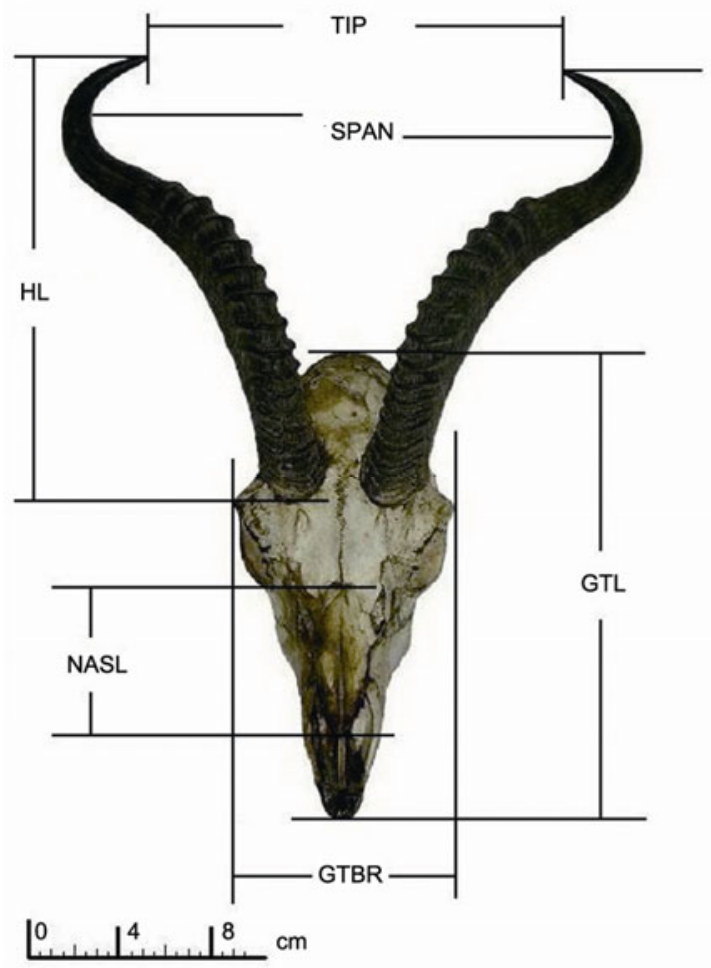

Figure 2 Configuration of skull. HL-Horn Length; TIP-Tip to Tip Distance; SPAN-Greatest Width between Horns; NASL-Length of Nasal Bone; GTL-Greatest Skull Length; GTBR-Greatest Breadth.
To perform the multivariate analysis, we produced a data set in which no less than 3 characters had been measured for all individuals, and this was done by dropping specimens with less than 3 measurable characters from the data set.

The remaining data set includes data of 65 individuals as below: 3 belong to the museum collection of the Institute of Zoology(IOZ), Chinese Academy of Sciences (CAS), IOZ/RAS and The Bird Island National Natural Reserve respectively (the former two designated Museum IOZ, the third Museum BI); 35 were designated group MODERN, in which 21 was collected during the field surveys in recent years and 14 belong to the private collection of local herdsmen; 8 (collected in areas around the Qinghai Lake in the 1990's, exact localities unknown, here designated group NPIB/CAS) were provided by Northwest Plateau Institute of Biology (NPIB), CAS; and 5 (collected in areas around the Qinghai Lake in the 1990's, exact localities again unknown, here designated group IOZ/CAS) are stored in the mammal department of IOZ/CAS. In addition, we used the measurements of 10 skulls from the Natural History Museum (London) and 4 skulls from the IOZ/RAS in St Petersburg (formerly Leningrad), as reported in Groves [19] (Figure 3).

\subsection{Data analysis}

Skull length (SL) was dropped from the list of characters because skulls were frequently worn or broken and hence often not measurable. Divergence of cranial characters among different groups was evaluated by using Mayr's [28] coefficient of difference ( $C D=\frac{M_{1}-M_{2}}{S D_{1}+S D_{2}}$ ), and Hierarchical Cluster Analysis, using an average linkage dendogram, was performed on the basis of Matrix Squared Euclidean Distance between the subsamples using IBM SPSS V19.0.

This research was carried out in accordance with the
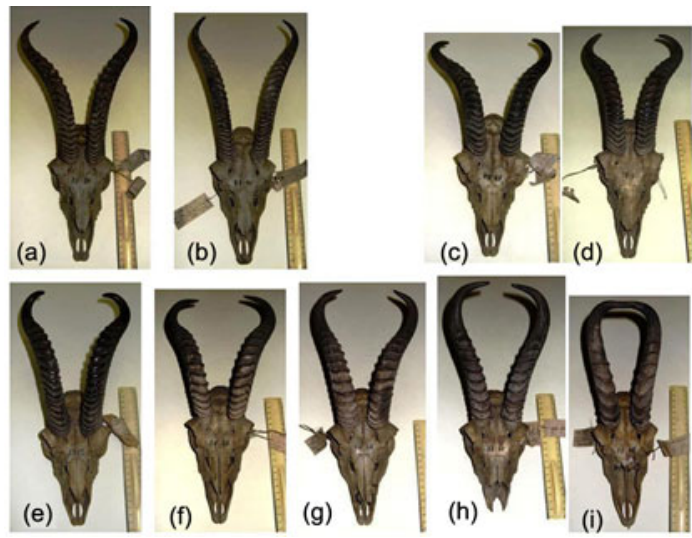

Figure 3 Skulls (a) and (b): P. p. diversicornis collected in the S. W. Gobi in the first decade of the 20th century. Skulls (c)-(i): P. p. przewalskii collected around the Qinghai Lake and on the Bukhan Gol (Buha River) in the late 19th century. 
principles and guidelines of the Chinese wildlife management authority, no gazelle was caught or hurt during this study.

\section{Result}

\subsection{Distribution of Przewalski’s gazelle}

Field surveys indicated that the current distribution range of Przewalski's gazelle is now restricted to the nine isolated local populations listed above: Yuanzhe, Bird Island, Qieji and Wayu populations in Gonghe County; Hudong, and Ganzihe population in Haiyan County; Hargai population in Gangcha County; Kuarma and Shengge population in Tianjun County (Figure 1).

\subsection{Subspecies in Przewalski's gazelle}

The means, standard deviations and number of characters measured are given in Table 1. Differences among samples were considerable and some of the coefficients of variation reached Mayr's subspecies level (Table 2).

In Figure 4, the samples used for the Hierarchical Cluster Analysis are P. p. przewalskii (PRZEWALSKII), P. p. diversicornis (DIVERSICORNIS), the "MODERN" sample, IOZ/CAS and NPIB/CAS. The average linkage dendogram shows $P$. p p przewalskii being strongly distinct from all other populations while the others close to each other; the "MODERN" collection is close to $P$. p. diversicornis rather than to $P$. p. przewalskii; the IOZ/CAS and NPIB/CAS skulls vary in their affinities, though the latter could preferentially be identified as P.p. diversicornis, the former as $P$. p. przewalskii.

In subsequent analyses (Figure 5), we separated the WAYU samples from the "MODERN" samples, again, the Museum BI and Museum IOZ skulls were added as comparison. Hierarchical Cluster Analysis indicates that, all samples fell into two clades: (1) DIVERSICORNIS, MODERN, WAYU and NPIB/CAS (2) PRZEWALSKII, IOZ/CAS, Museum IOZ and Museum BI, the two clades

Table 1 Measurements of the cranial traits of Przewalskii gazelle

\begin{tabular}{|c|c|c|c|c|c|c|}
\hline & HL & TIP & SPAN & NASL & GTL & GTBR \\
\hline PRZEWALSKII & $181.4 \pm 25.01(10)$ & $54.3 \pm 46.97(10)$ & $130.5 \pm 40.12(10)$ & $57.7 \pm 1.92(10)$ & $198.8 \pm 7.19(10)$ & $96.6 \pm 3.07(10)$ \\
\hline DIVERSICORNIS & $233.1 \pm 12.27(4)$ & $134.8 \pm 36.54(4)$ & $184.1 \pm 26.84(4)$ & $64.2 \pm 2.25(4)$ & $220.3 \pm 5.69(4)$ & $100.7 \pm 2.69(4)$ \\
\hline WAYU & $227.7 \pm 11.08(6)$ & $180.7 \pm 22.92(6)$ & $220.2 \pm 16.98(6)$ & $61.0 \pm 1.5(3)$ & $201.2 \pm 1.71(3)$ & $96.6 \pm 3.71(4)$ \\
\hline MODERN & $214.1 \pm 7.93(29)$ & $114.3 \pm 18.49(29)$ & $153.3 \pm 20.45(29)$ & $64.2 \pm 3.25(23)$ & $211.2 \pm 7.86(20)$ & $103.8 \pm 6.65(27)$ \\
\hline IOZ/CAS & $200.2 \pm 9.99(4)$ & $70.9 \pm 15.48(4)$ & $118.7 \pm 13.47(4)$ & $60.9 \pm 3.37(4)$ & $202.3 \pm 1.27(4)$ & $96.1 \pm 1.91(4)$ \\
\hline NPIB/CAS & $215.2 \pm 9.42(7)$ & $128.9 \pm 26.32(6)$ & $158.1 \pm 14.24(7)$ & $63.5 \pm 3.16(6)$ & $206.2 \pm 4.66(7)$ & $106.1 \pm 1.91(7)$ \\
\hline
\end{tabular}

a) P. p. przewalskii: collected around the Qinghai Lake and on the Bukhan Gol (Buha River) in the late 19th century; P. p. diversicornis: collected in the S. W. Gobi in the first decade of the 20th century; WAYU: collected (picked up) in the Wayu region, first decade of the 21st century; MODERN: collected (picked up) elsewhere around Qinghai Lake, first decade of the 21st century; IOZ/CAS: collection of the Institute of Zoology, Chinese Academy of Sciences, Beijing, during the 20th century; NPIB/CAS: collection of the Northwest Plateau Institute of Biology, Xining, during the 20th century. Data presented as Mean \pm SD $(n), \mathrm{mm}$.

Table 2 Coefficients of difference of cranial traits in Prezwalskii gazelle $(\mathrm{mm})^{\mathrm{a})}$

\begin{tabular}{|c|c|c|c|c|c|}
\hline & DIVERSICORNIS & WAYU & MODERN & IOZ/CAS & NPIB/CAS \\
\hline \multirow[t]{4}{*}{ PRZEWALSKII } & $1.39(\mathrm{HL})$ & $1.28(\mathrm{HL})$ & & & 1.91(GTBR) \\
\hline & 1.56(NASL) & 1.81(TIP) & & & \\
\hline & 1.67(GTL) & 1.57(SPAN) & & & \\
\hline & & 1.90 (NASL) & & & \\
\hline \multirow[t]{2}{*}{ DIVERSICORNIS } & & $2.58(\mathrm{GTL})$ & & $1.48(\mathrm{HL})$ & $1.36(\mathrm{GTL})$ \\
\hline & & & & $1.62(\mathrm{SPAN})$ & \\
\hline \multirow[t]{3}{*}{ WAYU } & & & $1.60(\mathrm{TIP})$ & $1.30(\mathrm{HL})$ & 1.99 (SPAN) \\
\hline & & & $1.79(\mathrm{SPAN})$ & 2.86(TIP) & 1.69 (GTBR) \\
\hline & & & & 3.33(SPAN) & \\
\hline MODERN & & & & $1.28(\mathrm{TIP})$ & \\
\hline \multirow[t]{2}{*}{ IOZ/CAS } & & & & & 1.39 (TIP) \\
\hline & & & & & $1.42(\mathrm{SPAN})$ \\
\hline
\end{tabular}

a) P. p. przewalskii: collected around the Qinghai Lake and along the Bukhan Gol (Buha River) in the late 19th century; P. p. diversicornis: collected in the S. W. Gobi in the first decade of the 20th century; WAYU: collected (picked up) in the Wayu region, first decade of the 21st century; MODERN: collected elsewhere around the Qinghai Lake, first decade of the 21st century; IOZ/CAS: collection of the Institute of Zoology, Chinese Academy of Sciences during the 20th century; NPIB/CAS: collection of the Northwest Plateau Institute of Biology during the 20th century. 


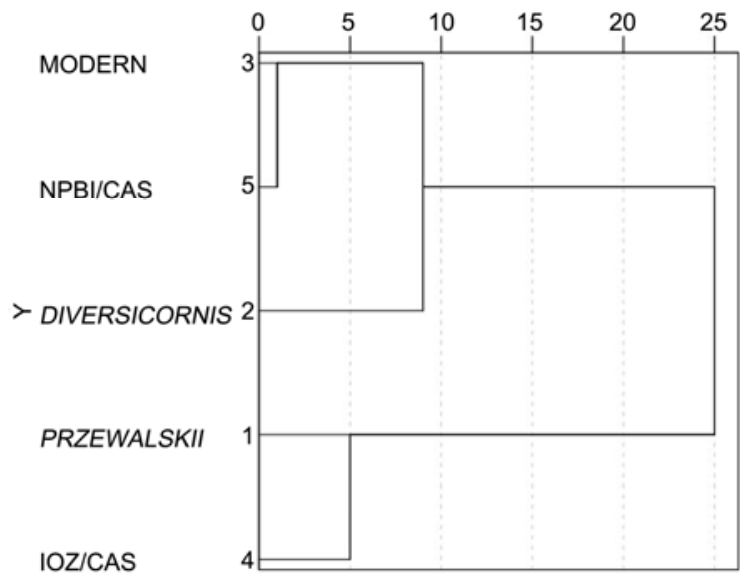

Figure 4 Phenogram of similarity between groups of Przewalskii gazelle by cranial traits resulted from IBM cluster analysis: Euclidean distance used; PRZEWALSKII: collected around the Qinghai Lake and along the Bukhan Gol (Buha River) in the late 19th century; DIVERSICONIS: collected in the S. W. Gobi in the first decade of the 20th century; WAYU: collected (picked up) in the Wayu region, first decade of the 21st century; MODERN: collected (pickup) elsewhere around Qinghai Lake, first decade of the 21st century; IOZ/CAS: collection of the Institute of Zoology, Chinese Academy of Sciences, Beijing, during the 20th century; NPIB/CAS: collection of the Northwest Plateau Institute of Biology, Xining, during the 20th century.

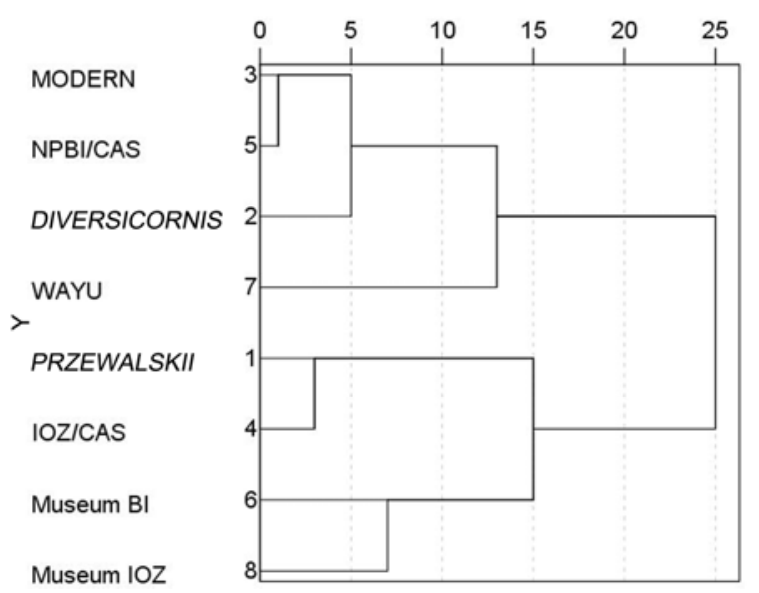

Figure 5 Phenogram of similarity between groups of Przewalskii gazelle by cranial traits resulted from IBM cluster analysis: Euclidean distance used; PRZEWALSKII: collected around the Qinghai Lake and along the Bukhan Gol (Buha River) in the late 19th century; DIVERSICONIS: collected in the S. W. Gobi in the first decade of the 20th century; WAYU: collected (pickup) in the Wayu region, first decade of the 21st century; MODERN: collected (picked up) elsewhere around the Qinghai Lake, first decade of the 21st century; IOZ/CAS: collection of the Institute of Zoology, Chinese Academy of Sciences, Beijing, during the 20th century; NPIB/CAS: collection of the Northwest Plateau Institute of Biology, Xining, during the 20th century; Museum BI: Museum collection of the Bird Island National Natural Reserve; Museum IOZ: Museum collection of the Institute of Zoology, Chinese Academy of Sciences (CAS), Institute of Zoology(IOZ), Russian Academy of Sciences (RAS).

were strongly distinct from each other; the latter was identified clearly as $P$. p. przewalskii, while DOVERSOCORNIS, MODERN AND NPIB/CAS were relatively close to each other as $P$. p. diversicornis; the three museum skulls, two from the Museum IOZ/CAS and Museum IOZ/RAS, and the one from the Museum of Bird Island (Museum BI) were associated closely with the PRZEWALSKII samples rather than with any of the others. The main difference of $P . p$. diversicorni from $P$. p. diversicornis is in their average smaller size and smaller, somewhat less divergent horns, but the skulls were broader (Table 1, Figure 3).

We conclude that the Przewalski's gazelles in the Qinghai Lake region are heavily introgressed by $P$. p . diversicornis. Previous authors $[15,19]$ characterized the distribution of $P$. p. diversicornis as restricted to Gansu, nominotypical $P$. p. przewalskii being the taxon in the Kukunor (the Qinghai Lake) area. Shiakou is at approximately 1500 $\mathrm{m}$, whereas the Qinghai localities are around $3000 \mathrm{~m}$, and Shiakou is somewhat over $100 \mathrm{~km}$ NNE of Qinghai Lake. The apparent partial replacement of one taxon by another in the Qinghai Lake region is a puzzle which we will discuss below.

\subsection{Variations in Przewalskii gazelle in the Qinghai Lake region today}

The MODERN samples from the Qinghai Lake region are, as noted above, much closer to $P$. p. diversicornis (Figure 5); nonetheless they shown great variation in horn shape and minor differences in other skull structures (Table 1). At one extreme, some skulls with relatively less spreading horns with much more incurved tips more resemble P.p. przewalskii (e.g. Figure 6(a)); at the other extreme, however, there are skulls with much more spreading horns with less incurved tips (e.g. Figure 6(c)); others display a variety of character differences between the two extremes (e.g. Figure 6(b)).

The skulls from WAYU are significantly different from those from other localities; it is characterized by much more spreading horns even than P. p. diversicornis and with less incurved tips, but a comparatively short skull like $P$. p. przewalskii; differences from the other current populations reached the conventional subspecies level in terms of HL, SPAN, GTL and GTBR (Table 3).

Hierarchical Cluster Analysis also confirmed: "MODERN", P. p. diversicornis and "WAYU" form graded

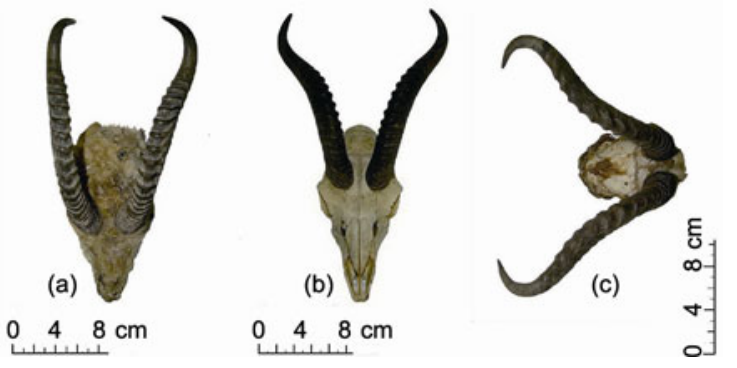

Figure 6 Variation in the form of horn shape of the remaining populations of P. p. diversicornis; the horn shape of Przewalski' gazelle living in QIEJI (a), HUDONG (b) and WAYU (c). 
Table 3 Coefficient of difference (CD) of skull characteristics of the remaining populations of $P$. p. diversicornis in Qinghai Lake region today)

\begin{tabular}{|c|c|c|c|c|c|c|}
\hline & QIEJI & YUANNZHE & HUDONG & HARGAI & BIRD I & TIANJUN \\
\hline \multirow[t]{4}{*}{ WAYU } & $2.30(\mathrm{TIP})$ & 1.49(TIP) & 1.89(TIP) & $2.09(\mathrm{TIP})$ & 1.59(TIP) & $1.71(\mathrm{TIP})$ \\
\hline & $2.19(\mathrm{SPAN})$ & 2.61(SPAN) & $1.90(\mathrm{SPAN})$ & $2.12(\mathrm{SPAN})$ & $1.86(\mathrm{SPAN})$ & $1.44(\mathrm{SPAN})$ \\
\hline & 1.60(GTL) & & 1.47(GTL) & & $2.01(\mathrm{GTL})$ & \\
\hline & 0.82 & 0.90 & 0.44 & 0.93 & 1.24(GTBR) & 1.44(GTBR) \\
\hline QIEJI & & 1.41 (TIP) & & & $1.36(\mathrm{GTBR})$ & \\
\hline HARGAI & & & & & & 1.36 (GTBR) \\
\hline
\end{tabular}

a) HUDONG-Hudong population; BRID I-Bird Island population; HARGAI-Hargai population; TIANJUN-Tianjun population; QIEJI-Qieji population; YUANZHE-Yuanzhe population; WAYU-Wayu population.

series, and that WAYU is clearly distinct from all other local populations which were, on the contrary, relatively close to each other (Figures 5,7).

As for the other six groups (i.e. excepted for "WAYU"), there were only minor differences between any two groups, in only a few cases reaching the conventional subspecies level, no more than would be expected on a chance level (Table 3). Hierarchical Cluster Analysis, using an average linkage dendogram, indicates that the local populations fell into four major clades: (1) HUDONG, Bird I, HARGAI, and TIANJUN, (2) YUANZHE, (3) QIEJI and (4) WAYU (Figure 7).

\section{Discussion}

A subspecies is a taxonomic subdivision of a species consisting of a geographic segment of that species that is morphologically different on average, but not absolutely, from other such geographic segments. There are fixed (inferentially) heritable differences between species, but not within subspecies of the same species [29]. As noted, the two "subspecies" of Przewalski's gazelle as they were in the

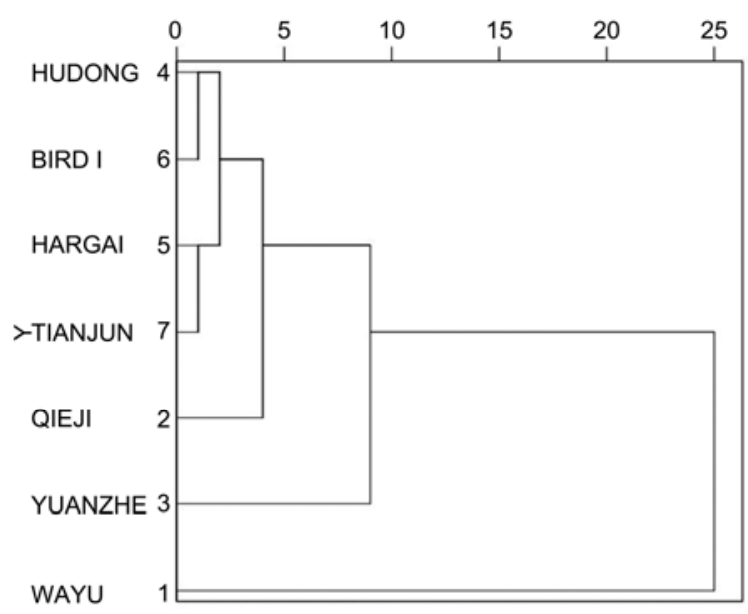

Figure 7 Phenogram of similarity between remained populations in Przewalskii gazelle by cranial traits resulted from IBM cluster analysis. Euclidean distance used; HUDONG-Hudong population; BRID I-Bird Island population; HARGAI-Hargai population; TIANJUN-Tianjun population; QIEJI-Qieji population; YUANZHE-Yuanzhe population; WAYUWayu population. early 20th century were diagnosably distinct, with no overlap in the known samples, and both Groves [19] and Leslie et al. [22] proposed that the gazelles might be better viewed as distinct species. However, considering the field situation we refer to the type of Przewalski's gazelle as subspecies.

Of the two, nominotypical $P$. p. przewalskii was formerly reported to be distributed in the Qinghai Lake region while P. p. diversicornis was described from considerably lower altitudes [15,19]. But, as noted above, we have never been able to spot any individual of $P$. p. przewalskii through our 18 years' intense field surveys around the Qinghai Lake, and expeditions in Gansu and Inner Mongolia failed to find any Przewalski's gazelles at all. Furthermore, with the exception of a few museum collections, all skulls, except for those from WAYU, analyzed in our study were much closer to $P$. p. diversicornis (see above). Consequently, the question of the actual historical distribution of $P . p$. diversicornis, and what had happened in the Qinghai Lake region, remained a mystery, the current distribution of Przewalski's gazelle being now restricted to the small isolated populations around the Qinghai Lake itself [1]. In 2008 Przewalski's gazelle was recategorized from Critically Endangered to Endangered on the IUCN Red List. The species is still threatened, however, because both the human population and domestic livestock are increasing and the habitat are further fragmented around Qinghai Lake. Furthermore, the gene flows in the isolated populations of Przewalski's gazelle are very limited [30].

Males in many species invest substantially in structures such as showy male adornments and weapons that function in male-male display and combat with rivals over access to females [31]. Both types of structures arise as a result of selection generated by competition over access to reproduction [31-33]. These structures can attain extreme proportions and diversified in form [34] and natural selection may favor the evolution of morphological differences that reduce the negative effects of competition. Modern considerations on sexually selected traits have focused primarily on ornaments [35,36]. In our case, however, the main mechanism which will have favored the fitness of $P . p$. diversicornis over $P$. p. przewalskii in recent times was certainly the form of horn shape as a weapon in male-male competition. Males with the largest and most elaborate horns as weapons are generally expected to achieve the highest reproductive suc- 
cess; the weapons are used to defend critical resources that directly or indirectly translated into mating opportunities [34].

$P$. p. przewalskii was of smaller size than $P$. p. diversicornis and had smaller, much less divergent horns. We hypothesise that, as climate warming speeded up during the 20th century, the environment formerly inhabited by $P . p$. diversicornis became unsuitable, and the populations spread into higher altitudes, tracking suitable habitat, reaching the region around Qinghai Lake by the 1990s. Larger size and in particular the larger and much more spreading horns with less incurved tips gave $P$. p. diversicornis an advantage over the indigenous $P$. p. przewalskii in fighting for mates in the Qinghai Lake region. We cannot as yet infer whether the advantage was entirely through sexual selection, or whether natural selection was involved. If the former was true; then the breeding of diversicornis males with przewalskii females would exclude przewalskii from breeding. Further breeding of diversicornis males with backcross females for several generations, would gradually spread the gene of diversicornis genotype in the population. If the second scenario was true, then it would have been the entire population, rather than just males, be replaced by diversicornis. These two scenarios could be tested by DNA analysis of both living animals and old museum specimens: if tested individuals in the present-day population of the Qinghai Lake region possess both $\mathrm{nDNA}$ and mtDNA characteristic of $P$. p. diversicornis, then clearly the natural selection hypothesis is supported. Whereas if their mtDNA is that of $P$. $p$. the przewalskii, and only their $\mathrm{nDNA}$ is that of diversicornis, then the sexual selection hypothesis is favoured.

Smaller population sizes resulting from severe habitat destruction, illegal hunting and livestock paddocks since the midst of the 20th century may have resulted in an Allee effect [38], which would contribute to the vulnerability and further increase the risk of local extinctions of $P . p$. przewalskii, giving further advantage to $P$. p. diversicornis. In any case, $P$. p. przewalskii may well now be functionally extinct over its entire range.

The remained populations of the Przewalskii gazelle in Qinghai Lake region are much closer to $P$. $p$. diversicornis; they do show minor variation in horn shape other skull structures, and the distribution patterns of the local populations are largely in accordance with the observed pattern of genetic differentiation [30]. The exception is the Wayu population, which is fully distinct (100\%) from all other populations of the species. Furthermore, individuals of Wayu population are much smaller (skull lengths do not overlap) than $P . p$. diversicornis; thus, unexpectedly, it meets the standard of subspecific differentiation. Two scenarios are possible to explain the existence of this distinctive population: (1) this distinctive taxon has always been present, previously undetected, in the Wayu area; or (2) for some reason it has only recently differentiated as a result of its increasing isolation from other populations- anthropogenic landscapes certainly do influence various evolutionary processes, such as gene flow and population structure [30]. Again, we need molecular data to approach this problem, and we will discuss this further in a future publication.

\section{Conservation recommendation}

For effective conservation of endangered species, it is important to identify evolutionarily significant units (ESUs) [38] within species; conservation actions may be effectively implemented. One obvious direction for future research would acknowledge that most of the remaining populations of Przewalski's gazelle in the Qinghai Lake region are a hybrid population between two subspecies, and are considerably closer to $P . p$. diversicornis than to the previously indigenous $P$. p. przewalskii as there has been no sign of any individual of the latter for the last two decades. The Wayu population is worthy of special conservation attention, and urgently needs to be fully investigated.

As a consequence of human activity, the habitats of Przewalski's gazelles remain in the wild around the Qinghai Lake had become fragmented into several isolated patches by the end of the 20th century [6,7]. Throughout the last century hunting was the primary cause of the decline in population size of the gazelle. Although hunting has been brought under control during the last two decades, the ever-increasing speed of urbanization, intensified stocking rate, construction fenced paddocks appear halt further recovery of the gazelle. We recommend the following measures for the development of conservation strategies for Przewalski's gazelle in the Qinghai Lake region: (1) Hudong, Hargai and Bird Island populations, the Yuanzhe population, the Tianjun population and the Qieji population, and the newly discovered Wayu population should be treated as five distinct management units (MUs), and particularly the Wayu population should be treated as an ESU. Special reserves should be established, in which paddock fencing and livestock grazing should be strictly banned within their ranges, and habitat corridors among reserves should be taken into consideration and established. (2) All possible causes of the gazelle's decline, such as hunting, wolf predation, resource competition with livestock, disease, and starvation in winter and early spring should be addressed systematically in order to facilitate the recovery of the populations so that they would serve as a source for a future reintroduction program. Meanwhile, search for sites that are suitable for ex situ conservation in order to restore the gazelle's population within its historical range, including Gansu, Ordos and northwest China should be carried out for long term reintroduction program. (3) Finally, a large scale field survey should be carried out for any possibility that there may be some remnant individuals of $P$. p. przewalskii somewhere inside or outside the Qinghai Lake region. 
This work was supported by the Key Program of Knowledge Innovation Program of Chinese Academy of Sciences (KSCX2-EW-Z-4), Sir Peter Scott Fund of SSC/IUCN and National Natural Science Foundation of China (30670267, 30430120). We thank Wu Yonglin, Li Weiping, Shang Jing, Karima Abdurahman, Hu Junhua, Li Chunlin, Li Feng, Ping Xiaoge, Kaola for their assistance on the field. This work would not have been possible without the invaluable assistance of the local Tibetan herdsmen, to whom we extend our many thanks. We are very grateful to Roberto Portela Miguez. (Mammal Section, Natural History Museum, London) for providing us the information on the origin and date of the specimen of P. $p$. diversicornis in that collection. We also thank Parida Isaac, Kawsar Amman and Qughlukh Mardan for their attention and generosity during our research work.

1 Jiang Z. Przewalski's Gazelle. Beijing: China Forestry Publishing House, 2004

2 Hu J, Ping X, Cai J, et al. Do local communities support the conservation of endangered Przewalski's gazelle? Eur J Wildlife Res, 2010, 56: $551-560$

3 Allen G. Natural History of Central Asia. The Mammal of China and Mongolia. New York: American Museum of Natural History, 1940

4 Jiang Z, Feng Z, Wang Z. Przewalski's gazelle in China. Conserv Biol, 1996, 10: 324-325

5 Mallon D P, Kingswood S C. Antelopes. Part 4: North Africa, the Middle East and Asia. Global Survey and Regional Action Plans. SSC Antelope Specialist Group. IUCN, Gland, Switzerland and Cambridge, UK, 2001

6 Jiang Z, Li D, Wang Z. Population declines of Przewalski's gazelle around Qinghai Lake, China. Oryx, 2000, 34: 129-135

7 Jiang Z, Feng Z, Wang Z, et al. Historical and current distributions of Przewalski's gazelle. Acta Theriologica Sin, 1995, 15: 241-245

8 Jiang Z, Li D, Wang Z, et al. Population structure of Przewalski's gazelle around the Qinghai Lake, China. Acta Zool Sin, 2001, 47: $158-162$

9 Wang X, Schaller G. Status of large mammals in western Inner Mongolia, China. Journal of East China Normal University, Natural Sciences, Special Issue of Zoology, 1996, 12: 93-104

10 Schaller G B. Wildlife of the Tibetan Steppe. Chicago: The University of Chicago Press, 1998

11 ICUN. 2012 IUCN Red List of Threatened Animals. IUCN, Gland. Available http://www.iucnredlist.org/, 2012

12 Li C, Jiang Z, Ping X, et al. Current status and conservation of the Endangered Przewalski's gazelle Procapra przewalskii, endemic to the Qinghai-Tibetan Plateau, China. Oryx, 2012, 46: 145-153

13 Lydekker R, Blaine G. Catalogue of Ungulate Mammals in the British Museum (Natural History), 1914

14 Ellerman J R, Morrison-Scott T C S. Checklist of Palearctic and India Mammals, 1758 to 1946. London: British Museum (Natural History), 1951

15 Stroganov S U. Systematics and distribution of some antelopes of Central Asia. Bull.Mosk.Obshchestva ispyt.prirody, otd.biol, Moscow, 1949, 54: 15-26

16 Zhang J, Wang Z Y. Fauna of Qinghai Province. Acta Zool Sin, 1963 ,
15: $125-138$

17 Lei R, Hu Z, Jiang Z, et.al. Phylogeography and genetic diversity of the critically endangered Przewalski's gazelle. Anim Conserv, 2003, 6: $361-367$

18 Yang J, Jiang Z. Genetic diversity, population genetic structure and demographic history of Przewalski's gazelle (Procapra przewalskii): Implications for conservation. Conserv Genet, 2011, doi: 10.1007/ s10592-011-0244-7

19 Groves C P. On the gazelles of the genus Procapra Hodgson, 1846. Zeitschrift fur Saugetierkunde, 1967, 32: 144-149

20 Wallace H F. The Big Game of Central and Western China. Chippenham,Wilts, UK: Anthony Rowe Ltd, 1913

21 Groves C P, Paterson J D. Testing hominoid phylogeny with the PHYLIP program. J Hum Evol, 1991, 20: 167-183

22 Leslie D M, Groves C P, Abramov A V. Procapra przewalskii (Artiodactyla: Bovidae). Mammalian Species, 2010, 42: 124-137

23 Zhou L S, Yang W. Discussion of the climatic change in recent 500 years and dropping of lake water-level, Qinghai Lake drainage basin. Journal of Lake Sciences, 1992, 3: 25-31

24 Zhou L H, Chen G, Peng M. Impact of human activities on the decline of water level, Qinghai Lake. Journal of Lake Sciences, 1992, 3: 32-37

25 Corbet G. Patterns of subspecies variation. Symposium of the Zoological Society of London, 1970, 26: 105-116

26 Jiang Z, Feng Z, Wang Z. Historical and current distribution of Przewalski's gazelle. Acta Zool Sin, 1995, 4: 241-245

27 Lei R, Jiang Z, Hu Z, et al. Phylogenetic relationships of Chinese antelopes (subfamily Antilopinae) based on mitochondrial ribosomal RNA gene sequences. J Zool, 2003, 261: 227-237

28 Mayr E, Linsley E G, Usiger R L. Methods and Principles of Systematic Zoology. New York: Mcgraw-Hill Book Inc, 1953

29 Mayr E. Population, Species, and Evolution; An Abridgment of Animal Species and Evolution. Massachusetts: Harvard University Press, 1970

30 Yang J, Jiang Z, Zeng Y, et al. Effect of anthropogenic landscape features on population genetic differentiation of Przewalski's gazelle: Main role of human settlement. PLoS One, 2011, 6: e20144.

31 Darwin C. The Descent of Man. London: William Clowes and Sons. Inc, 1871

32 West-Eberhard M J. Sexual selection, social competition, and evolution. Proceedings of the American Philosophical Society, 1976, 123: 222-234

33 Eberhard M J. Sexual selection, social competition, and speciation. Q Rev of Biol, 1983, 58: 155-183

34 Emlen D J. The evoulotion of animal weapons. Annu Rev Ecol Evol S, 2008, 39: 387-413

35 Andersson M. Sexual Selection. Princeton: Princeton University Press, 1994

36 Andersson M, Iwasa Y. Sexual selection. Trends Ecol Evol, 1996, 11: 53-58

37 Courchamp F, Clutton-Brock T H, Grenfell B. Inverse density dependence and the Allee effect. Trends Ecol Evol, 1999, 14: 405-410

38 Conner J, Hartl D. A Primer of Ecological Genetics. Sunderlan: Sinauer Associates, Inc. USA, 2004

Open Access This article is distributed under the terms of the Creative Commons Attribution License which permits any use, distribution, and reproduction in any medium, provided the original author(s) and source are credited. 